\title{
MEDIDAS PROTETIVAS E DE SEGURANÇA DO MEIO AMBIENTE DE TRABALHO E O ENFRENTAMENTO DA COVID-19
}

\author{
Sônia Maria Rodrigues do Nascimento ${ }^{1}$ \\ Gizelda Rodrigues de Araújo ${ }^{2}$
}

RESUMO: O presente artigo tem por objetivo discutir sobre as normas de segurança e saúde do trabalhador no ambiente de trabalho, apontando algumas medidas protetivas e de segurança que minimizariam as consequências desastrosas tanto para o trabalhador quanto para o INSS, ressaltando ainda sobre o enfrentamento da covid-I9 no meio ambiente de trabalho e as medidas restritivas adotadas. Mesmo sabendo que o Brasil contém uma das legislações mais avançadas em matéria de saúde do trabalhador, por que ainda é assustador o número e acidentes e doenças no meio ambiente do trabalho? O referido estudo trata-se de uma pesquisa bibliográfica quanto ao procedimento, com uma abordagem qualitativa e exploratória com relação ao objetivo. Pautada num arcabouço teórico inerentes a doutrinas de autores que discorrem sobre o assunto, artigos, sites e a legislação brasileira. A pesquisa abordou sobre os diferentes tipos de meio ambientes, dando maior ênfase ao meio ambiente do trabalho, sobre os acidentes de trabalho, as medidas preventivas e discorreu sobre as medidas preventivas no contexto da Covid-i9. O resultado do estudo apontou que não basta a previsão do PPRA e PCMSO, mas o apontamento e cumprimento de medidas capazes de elidir ou reduzir o risco ocupacional e para tanto é preciso que o empregador tenha a obrigação de zelar pela conservação da saúde de seus empregados, sendo que quanto maior for a exposição do empregado a riscos ambientais do trabalho, maior deverá ser o cuidado e a prevenção de acidentes. Demonstrando ainda preocupação inerente ao enfrentamento do covid-I9 que trouxe várias consequências sobre o mercado de trabalho.

Palavras-Chave: Medidas Protetivas. Meio Ambiente de Trabalho. Acidente de Trabalho. Enfrentamento da Covid-I9.

ABSTRACT: This article aims to discuss the safety and health standards of workers in the workplace, pointing out some protective and safety measures that would minimize the disastrous consequences for both the worker and the INSS, also emphasizing the confrontation of covid-I9 in the work environment and the restrictive measures adopted. Even knowing that Brazil has one of the most advanced legislation in the field of worker health, why is the number of accidents and diseases in the workplace still scary? This study is a bibliographical research regarding the procedure, with a qualitative and exploratory approach in relation to the objective. Based on a theoretical framework inherent to the

\footnotetext{
I Doutora, especialização em Direito e Processo do Trabalho pela Universidade Anhanguera-Uniderp; Graduada em Direito pela UNIVERSO; Graduada em Pedagogia pela PUC-Goiás.

${ }^{2}$ Gizelda Rodrigues de Araújo. Especialista em Métodos e Técnicas de Ensino (UNIVERSO); Especialista em Biologia (UFLA); Especialista em Gestão Ambiental (FASEM); Pós-graduanda em Direito Civil (PUCMinas). Graduação em Licenciatura Plena em Pedagogia (UEG); Licenciatura Plena em Biologia (UEG); Licenciatura Plena em Física (UFG); Bacharelanda em Direito (UEG).
} 
doctrines of authors who discuss the subject, articles, websites and Brazilian legislation. The research addressed the different types of environments, giving greater emphasis to the work environment, workplace accidents, preventive measures and discussed preventive measures in the context of Covid-19. The result of the study showed that the provision of PPRA and PCMSO is not enough, but the appointment and fulfillment of measures capable of eliminating or reducing occupational risk and, for that, it is necessary that the employer has the obligation to ensure the preservation of the health of its employees, given that the greater the employee's exposure to environmental risks at work, the greater should be the care and prevention of accidents. It also demonstrates the concern inherent in facing the covid-19, which had several consequences on the labor market.

Keywords: Protective Measures. Work Environment. Work Accident Covid-ı9.

\section{INTRODUÇÃO}

A vida é considerada o bem maior, um direito fundamental na esfera jurídica brasileira. E a qualidade dessa vida no ambiente de trabalho é protegida pela Carta Magna de 88 , e por todas as demais normas infraconstitucionais existentes capazes de regulamentar o direito a saúde e a segurança no ambiente de trabalho.

Dessa forma, assumindo um caráter protetivo, os direitos fundamentais visam a garantia da proteção à vida, saúde, segurança, trabalho, previdência social, entre outros. ${ }^{3}$

No entanto, com muita frequência, a sociedade se depara com acidentes de trabalho que poderiam ter sido evitados se os empregadores não tivessem se omitido em zelar pela segurança de seus empregados quer porque não lhes prestou as informações devidas sobre os riscos da atividade ou por não ter oferecido treinamento adequado para operar os equipamentos e nem tão pouco fiscalizou os equipamentos de segurança do trabalho.

\footnotetext{
Assim, como frisou Cabanellas, "não é possível, admitir o sacrifício de vidas humanas pela simples necessidade de aumentar a produção ou para melhorá-la. É preciso ter em conta que a primeira condição que o patrão está obrigado a cumprir é a de assegurar que os trabalhadores se desenvolvam em um ambiente moral e rodeados da segurança e higiene próprias da condição e dignidade de que se revestem". (Nascimento, Amauri Mascaro, 2014, p. 86).
}

\footnotetext{
3 Os direitos fundamentais caracterizam-se como verdadeiras liberdades positivas, de observância obrigatória em um Estado Democrático de Direito, tendo por finalidade a melhoria de condição social dos trabalhadores (CF,ar.7º,"caput"), em prol de um marco regulatório mínimo de cidadania, o qual configura, um dos fundamentos da República Federativa do Brasil.

$\mathrm{O}$ art. I - dos Princípios fundamentais, traz em seus incisos IV “ os valores sociais do trabalho e da livre iniciativa”.
} 
Aos trabalhadores cabe interagir com essas medidas protetivas, fazendo uso de forma adequada dos equipamentos de proteção oferecidos gratuitamente pelos empregadores, não podendo se recusar a usar sem justificativa e caso o faça considera-se ato faltoso cabendo rescisão por justa causa.

Quanto ao estado, cabe criar políticas públicas, capaz de articular com eficiência no meio ambiente como um todo e em especial ao ambiente de trabalho, através da fiscalização e acompanhamento desses estabelecimentos com medidas preventivas tentando evitar os possíveis riscos à saúde do trabalhador proporcionando um ambiente produtivo e respeitador dos Direitos Humanos.

Nesse mesmo diapasão, vale ressaltar que em algumas funções a ameaça à integridade física do trabalhador é inerente ao tipo de serviço realizado, todavia, a legislação trabalhista impõe que se reduza ao máximo estes perigos, como pode se verificar no artigo I66 previsto na Consolidação das Leis Trabalhistas- CLT:

\footnotetext{
Art. 166- A empresa é obrigada a fornecer aos empregados, gratuitamente, equipamento de proteção individual adequado ao risco e em perfeito estado de conservação e funcionamento, sempre que as medidas de ordem geral não ofereçam completa proteção contra os riscos de acidentes e danos à saúde dos empregados. (Redação dada pela Lei no 6.514, de 22.12.1977).
}

Entende-se que as diversas leis que protegem os direitos humanos dos trabalhadores, visam colocar limites ao poder do empregador, embora este, através de seu poder diretivo, por ser o contratante, dê ordens que espera serem cumpridas.

Nesse sentido questiona-se: Mesmo sabendo que o Brasil contém uma das legislações mais avançadas em matéria de saúde do trabalhador, por que ainda é assustador o número e acidentes e doenças no meio ambiente do trabalho?

O presente artigo tem por objetivo discutir sobre as normas de segurança e saúde do trabalhador no ambiente de trabalho, apontando algumas medidas que minimizariam as consequências desastrosas tanto para o trabalhador quanto para o INSS, ressaltando ainda sobre o enfrentamento da covid-I9 no meio ambiente de trabalho.

A pandemia da covid-ı, doença causada pelo coronavírus da espécie SARSc-CoV2, provocou em curtíssimo intervalo de tempo profundas alterações sociais e econômicas por todo o mundo.

E complementando esse pensamento, Tupinambá(200I, p.4I), esclarece que: "ao longo do período de desenvolvimento de estratégias de enfrentamento de emergência de 
saúde pública, o Direito do Trabalho, tem sido sem dúvidas, uma das áreas mais dramaticamente afetadas em dezenas de países”.

Nesse sentido, ainda segundo a mesma autora, entende-se que o meio ambiente de trabalho, a compreender o sistema formado pelas condições físicas, psíquicas e organizacionais que circundam os indivíduos no desempenho de suas atividades profissionais, passou a figurar como um possível espaço de entronização e circulação do novo coronavírus, de modo que aquele risco agravado, presente na generalidade dos espaços naturais e artificiais, também passou a integrá-los e a condicionar decisivamente a qualidade de vida dos trabalhadores ali inseridos. ${ }^{4}$

Com a entronização e circulação do novo coronavírus nos espaços laborais constitui, em um contexto de transmissão comunitária de base antrópica e por meio de seres humanos, instituindo nesses espaços, um estado de "desequilíbrio sistêmico no arranjo das condições de trabalho e da organização do trabalho, de modo a ocasionar nos indivíduos ali ativados, "riscos intoleráveis à segurança física e mental [...] (maranhão, 2017, p.234).

Nessa Senda, o referido trabalho abordou sobre os diferentes tipos de meio ambientes, dando maior ênfase ao meio ambiente do trabalho, sobre os acidentes de trabalho, as medidas protetivas e discorreu sobre as medidas preventivas no contexto da Covid-I9.

O resultado do estudo apontou que não basta a previsão do PPRA e PCMSO, mas o apontamento e cumprimento de medidas capazes de elidir ou reduzir o risco ocupacional e para tanto é preciso que o empregador tenha a obrigação de zelar pela conservação da saúde de seus empregados, sendo que quanto maior for a exposição do empregado a riscos ambientais do trabalho, maior deverá ser o cuidado e a prevenção de acidentes.

Vale ressaltar que em decorrência desse período excepcional (pandemia do novo coronavirus) em que suscitam muitos desafios, mudanças acentuadas foram provocadas na sociedade, bem como adaptações invitáveis no modo de viver com muitas repercussões no mundo do trabalho, cogitando-se no momento que não haverá retorno ao normal.

\footnotetext{
${ }_{4}^{4}$ Segundo o conceito formulado por Norma Sulei Padilha, "O meio ambiente de trabalho compreende o habitat laboral onde o ser humano trabalhadro passa a maior parte de sua vida produtiva provendo o necessário para a sua sobrevivência e e desenvolvimento por meio de uma atividade e abrange a segurança e saúde dos trabalhadores, protegendo-o contra as formas de degradação e/ou poluição gerada no ambiente de trabalho.(TUPINAMBÁ, Carolina, 20or, p.59).
} 


\section{MEIO AMBIENTE}

Ambiente segundo o dicionário online 5 da língua portuguesa significa "que está ao redor, envolvendo pessoas ou coisas". A palavra ambiente vem do latim "ambiens” e significa " que rodeia”; De acordo com Machado (2013), ambiente significa uma ideia que se refere à adjacência que rodeia os seres vivos, possibilitando o desenvolvimento de suas circunstâncias vitais. E ainda segundo o mesmo autor, o ambiente é formado por diversas condições, tanto físicas como sociais, culturais e econômicas.

A Lei no 6.938/8I, art. $3^{\circ}$ inciso I, (Lei de Política Nacional do Meio Ambiente) por sua vez, define Meio ambiente como sendo: "O conjunto de condições, leis, influencias e integrações de ordem física, química e biológica, que permite, abriga, e rege a vida em todas as suas formas”. A Constituição Federal ao recepcionar a referida lei passou a entender que meio ambiente divide-se em físico ou natural, cultural, artificial e do trabalho.

$\mathrm{O}$ meio ambiente físico ou natural está previsto na $\mathrm{CF} / 88$, considerando a fauna, a flora, o solo, a atmosfera, água como os constituintes desse ambiente, com a seguinte redação:

Todos têm direito ao meio ambiente ecologicamente equilibrado, bem de uso comum do povo e essencial à sadia qualidade de vida, impondo-se ao Poder Público e à coletividade o dever de defendê-lo e preservá-lo para as presentes e futuras gerações. (BRASIL. Constituição 1988).

O ordenamento jurídico brasileiro consagra o meio ambiente natural como um ambiente ecologicamente equilibrado, direito difuso, essencial à sadia qualidade de vida, atribuindo também a todos, e não somente ao Estado, a preservação, conservação e manutenção do mesmo. "Preservar e restaurar os processos ecológicos essenciais e prover o manejo ecológico das espécies e ecossistemas ( art.225,§ Io,I)"; "proteger a fauna e a flora, vedadas, na forma da lei, as práticas que coloquem em risco sua função ecológica, provoquem a extinção de espécies ou submetam os animais a crueldade( $\operatorname{art.225,\S ~Iํ,VII)”.~}$

A Constituição Federal/88 reza em seu artigo 215 a seguinte redação: “ O Estado garantirá a todos o pleno exercício dos direitos culturais e acesso às fontes da cultura nacional, e apoiará e incentivará a valorização e a difusão das manifestações culturais”.

${ }^{5}$ https://www.dicio.com.br/ambiente/ 
Complementa com os §§ Iㅇ e 2으 respectivamente "O Estado protegerá as manifestações das culturas populares, indígenas e afro-brasileiras, e das de outros grupos participantes do processo civilizatório nacional". "A lei disporá sobre a fixação de datas comemorativas de alta significação para os diferentes segmentos étnicos nacionais.”

Observa-se mediante o exposto que se considera como constituintes do meio ambiente cultural o patrimônio cultural, artístico, arqueológico, paisagístico, manifestações culturais e populares.

E quanto ao meio ambiente artificial, foi considerado pela carta magma, o conjunto de edificações particulares ou públicas, principalmente urbanas.

Art. 182. A política de desenvolvimento urbano, executada pelo Poder Público municipal, conforme diretrizes gerais fixadas em lei, tem por objetivo ordenar o pleno desenvolvimento das funções sociais da cidade e garantir o bem-estar de seus habitantes. (Regulamento) (Vide Lei no I3.311, de II de julho de 2016).

Complementando esse pensamento o art. 21, inciso XX, (CF/88), "instituir diretrizes para o desenvolvimento urbano, inclusive habitação, saneamento básico e transportes urbanos"; Ainda à luz da CF/88 vem asseverar em seu artigo $5^{\circ}$ que todos são iguais perante a lei.

Art. $5^{\circ}$ Todos são iguais perante a lei, sem distinção de qualquer natureza, garantindo-se aos brasileiros e aos estrangeiros residentes no País a inviolabilidade do direito à vida, à liberdade, à igualdade, à segurança e à propriedade, nos termos seguintes:

XXIII - a propriedade atenderá a sua função social; $(\mathrm{CF} / 88)$.

E por último, temos o meio ambiente do trabalho, o qual é compreendido como o conjunto de condições existentes num local de trabalho relativo à qualidade de vida do trabalhador, previsto na Constituição Federal;

Art. $7^{\text {}}$ São direitos dos trabalhadores urbanos e rurais, além de outros que visem à melhoria de sua condição social: [...] XXXIII - proibição de trabalho noturno, perigoso ou insalubre a menores de dezoito e de qualquer trabalho a menores de dezesseis anos, salvo na condição de aprendiz, a partir de quatorze anos; (Redação dada pela Emenda Constitucional no 20, de 1998).

Temos ainda, o Sistema único de saúde, com suas várias atribuições, dentre elas a de colaborar na proteção do meio ambiente, nele compreendido o do trabalho. (art. 200, VIII, da Constituição). 


\section{I MEIO ANBIENTE DO TRABALHO}

O meio ambiente do trabalho num sentido mais amplo é o local de realização da atividade laboral, abrangendo as condições de trabalho, a sua organização e as relações intersubjetivas ali presentes. Nesse sentido, entende-se não se tratar de "uma construção teórica, mas de um direito fundamental do trabalhador resguardado constitucionalmente”.(MARANHÃO, 2017).

A definição legal de Meio Ambiente de Trabalho, está prevista no artigo 20o, inciso VIII e artigo 225, da Constituição Federal de 1988, a qual the conferiu caráter de direito fundamental, tornando clausula pétrea a proteção à saúde do trabalhador, como segue transcrito: "Art. 200. Ao sistema único de saúde compete, além de outras atribuições, nos termos da lei: (...)VIII - colaborar na proteção do meio ambiente, nele compreendido o do trabalho".

Art. 225. Todos têm direito ao meio ambiente ecologicamente equilibrado, bem de
uso comum do povo e essencial à sadia qualidade de vida, impondo-se ao Poder
Público e à coletividade o dever de defendê-lo e preservá-lo para as presentes e
futuras gerações.(BRASIL, Constituição Federal, 1988)

Em nosso ordenamento jurídico, a proteção legal ao meio ambiente de trabalho encontrase respaldada pela Constituição Federal, a Lei n. 6.938, de 3i de agosto de 198I da Política Nacional do Meio Ambiente, a Consolidação das Leis do Trabalho, alterada pela Lei no 6.514, de 22 de dezembro de 1977; a Portaria $\mathrm{n}^{-}$3.214, de 8 de junho de 1978, e as Normas Regulamentadoras - NR do Ministério do Trabalho e Emprego entre outras.

E partindo dessa premissa de que o local de trabalho, é por sua vez, o ambiente onde o trabalhador passa a maior parte de sua vida, e considerando que, o bem mais caro para todo e qualquer ser vivente é a vida, fica subentendido que deve ser um lugar seguro, digno, capaz de garantir aos trabalhadores os direitos fundamentais humanos como determina a Carta Magna de 88.

A dignidade da pessoa humana é considerada como valor supremo, que revela caráter único e insubstituível de cada um, é justamente aqueles inatos e imanentes à pessoa humana, ou seja, aqueles que toda pessoa possui pelo simples fato de ter nascido nesta condição "humana", temos como exemplo a vida, o respeito, a segurança, o bem-estar, e a saúde são direitos considerados inafastáveis, inalienáveis e imprescritíveis e portanto, merecedor de respeito e considerações por parte de todo ser vivente no planeta. 
Dentro dessa estrutura, encontra-se o meio ambiente do Trabalho, onde Amauri Mascaro Nascimento define o como:

"O meio ambiente de trabalho é exatamente, o conjunto máquina-trabalho: as
edificações do estabelecimento, equipamentos de proteção individual, iluminação,
conforto térmico, instalações elétricas, condições de salubridade ou insalubridade,
de periculosidade ou não, meios de prevenção à fadiga, outras medidas de proteção
ao trabalhador, jornadas de trabalho e horas extras, intervalos, descansos, férias,
movimentação, armazenagem e manuseio de materiais que formam o conjunto de
condições de trabalho etc." (Nascimento, 20I4, p. 868).

Nesse sentido, o trabalhador se torna a peça fundamental inserida nesse conjunto complexo formado pelo Meio ambiente do trabalho, necessitando de proteção jurídica à sua saúde e segurança, como estabelece a Carta Magna de 88, declarando que são direitos dos trabalhadores "redução dos riscos inerentes ao trabalho por meio de normas de saúde, higiene e segurança.", bem como "os valores sociais do trabalho e da livre iniciativa".

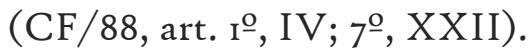

A proteção à vida humana está diretamente ligada ao direito a uma vida com qualidade que deveria ser assegurada por políticas de saúde e segurança, através de medidas prevencionistas e protetivas, voltadas para a redução ou eliminação dos riscos, viabilizando

assim a qualidade de vida dos trabalhadores no meio ambiente de trabalho. Entretanto, a realidades está distante desse ideário de segurança e saúde no meio ambiente de trabalho. A concorrência desenfreada por um espaço no mercado de trabalho faz com que os empregadores tenham como ideário apenas o lucro, se esquecendo da obrigação de cumprir as normas e medidas protetivas de saúde e segurança no ambiente de trabalho, tipificado no nosso ordenamento jurídico causando assim direta ou indiretamente um número vultuoso de acidente de trabalho na nossa sociedade atual.

\section{ACIDENTE DE TRABALHO}

Entende-se por acidente, segundo Benedito Cardella , como a ocorrência anormal que contém evento danoso. Danos ou perdas, ainda que desprezíveis, sempre ocorrem. (Cardella, 2014, p. 235)

$\mathrm{Na}$ definição legal dada pela Lei no 8.213/91 em seu art.19 "Acidente do trabalho é todo aquele que ocorre pelo exercício do trabalho, a serviço da empresa, ou pelo exercício do trabalho dos segurados referidos no artigo II, inciso VII desta 
lei, provocando lesão corporal, perturbação funcional ou doença que cause a morte, perda ou redução, permanente ou temporária, da capacidade para o trabalho.”

Além do ato do acidente, a lei também considera, conforme o art.20,I da mesma lei, as doenças profissionais que são as patologias existentes em virtude do exercício trabalho e as patologias adquiridas desencadeada pelo exercício do trabalho peculiar a determinada atividade desenvolvida pelo trabalhador.

Acidente de trabalho é considerado gênero do qual se extrai três espécies, dentre as nomenclaturas, temos: Acidente típico, acidente atípico e acidente de trajeto.

Acidente típico, é aquele que ocorre com o trabalhador no local e horário de trabalho, em razão do serviço executado; Acidente atípico é considerado aquele que contribuiu diretamente para o surgimento das doenças ocupacionais e doenças do trabalho; e o acidente de trajeto é em que o trabalhador sofre no percurso de deslocamento entre a residência e o local de trabalho, vice - versa que vier a sofrer. Ainda é uma triste realidade os casos de acidentes de trabalho no Brasil ${ }^{6}$, visto que entre 2007 e 2013 ocorreram 5 milhões de acidentes, em que $45 \%$ acabaram em morte, em invalidez permanente ou afastamento temporário do emprego.

Neste período, o Instituto Nacional do Seguro Social (INSS) desembolsou quase R $\$$ 58 bilhões com indenizações aos acidentados (dados do site Jus Brasil - 2016). "Segundo estimativas globais da Organização Internacional do Trabalho (OIT), 7acidentes e doenças de trabalho implicam perda anual de cerca de $4 \%$ do Produto Interno Bruto, o que, no caso do Brasil, equivaleria, em números de 2017, a $\mathrm{R} \$ 264$ bilhões”, revela o procurador do Trabalho Luís Fabiano de Assis, responsável pelo observatório.

Pode se afirmar que muito se vê, porém pouco se lê sobre acidentes do trabalho. No site “A TARDE” da UOL, do dia 12 de Maio de 2019, vem ressaltar que o Brasil ocupa a quarta posição no ranking mundial, onde a Previdência Social registra por ano cerca de 700 mil casos e ainda segundo dados do Observatório Digital de Segurança e Saúde do trabalho

\footnotetext{
${ }^{6}$ https://saberalei.jusbrasil.com.br/artigos/34III4233/acidente-do-trabalho-caracteristicas-e-direitos-dotrabalhador

7 Justiçado Trabalho - Tribunal Superior do trabalho -

http://www.tst.jus.br/web/trabalhoseguro/programa/-/asset_publisher/oSUp/content/perdas-comacidentes-de-trabalho-custam-mais-de-r-26-bi-da-previdencia
} 
, o país chega a contabilizar uma morte por acidente em serviço a cada três horas e 40 minutos.

Segundo dados da Previdência oficial, entre 2014 e 2018 foi registrado no Brasil I,8 milhão de afastamentos por acidente de trabalho e 6,2 mil óbitos ${ }^{8}$. "E isso se deve ao fato de que as mortes, acidentes e doenças relacionadas ao trabalho são uma questão de saúde pública muitas vezes "invisível", e até "naturalizada", dizem os especialistas."

Observa-se que os dados são preocupantes, tanto no tocante as consequências físicas e psicológicas dos acidentados quanto aos prejuízos causados ao INSS e possivelmente os prejuízos suportados pela empresa.

Os custos dos acidentes de trabalho são transformados em despesas enormes, gerando uma cadeia de eventos e um custo altíssimo para a sociedade, vez que, quando é registrado um acidente de trabalho deve ser mobiliza muitos órgãos, para auxiliar a vítima no momento do acidente como: Ministério do Trabalho, o Corpo de Bombeiro, polícia, hospital, médicos, enfermeiros, etc. Depois desse primeiro socorro e de cirurgia se necessário deverá ser feito encaminhamentos domiciliares com medicamento, assistência psicológica e de assistente social.

Entretanto, com todo esse envolvimento de aparelhos, profissionais e recursos financeiros, o maior custo e prejuízo acabam sendo para o trabalhador que sofreu o acidente.

E de forma reflexa essas dores se estendem aos familiares, porque os danos ou sequelas deixadas no trabalhador são imensuráveis. Não tem preço para aquele que perde um braço, ou uma perna, ou quando chega ao óbito. Quanto deve ser pago para o filho que perdeu o pai no acidente de trabalho? Ou para a viúva que perdeu o marido? Ou para uma mãe que perdeu um filho? A realidade é que na maioria das vezes o que morreu era o único provedor da família e a sua falta acaba deixando os seus dependentes a margem da sociedade.

Dentro dessa realidade severa, capaz de transformar a vida do trabalhador de forma trágica, o acidente de trabalho, muitas vezes quando não mata, deixa sequelas definitivas nas vítimas tornando-os de forma improducente para a realização de qualquer trabalho e até mesmos em muitos casos deixando-os incapazes de realizarem sozinhos os movimentos

\footnotetext{
${ }^{8}$ dados da Previdência oficial, entre 2014 e 2018 foi registrado no Brasil I,8 milhão de afastamentos por acidente de trabalho e 6,2 mil óbitos. Extra Classe. Publicado em i4 de maio de 2019; https://www.extraclasse.org.br/geral/2019/o5/pais-pode-assumir-lideranca-em-acidentes-detrabalho/\#: :text=De\%20acordo\%2ocom\%2odados\%20da,\%C3\%A9\%20um\%20assunto\%2obem\%20amplo.
} 
básicos mínimos de sobrevivência como alimentar-se ou fazer a higiene pessoal necessitando sempre da assistência de um terceiro. Existem ainda as sequelas de natureza psíquica, causando sofrimento para o trabalhador que sofreu o acidente diretamente por se sentir inútil para si e para a sociedade e finda transferindo esse sofrimento de forma reflexa os familiares.

$\mathrm{Na}$ seara normativa temos um arsenal de leis e normas que regulamentam a saúde e segurança no ambiente de trabalho tanto as normas constitucionais quanto as infraconstitucionais. Do outro lado tem-se o MPT, Sindicato, Anvisa, Justiça do Trabalho, CIPA e outros que fiscalizam o cumprimento dessas normas.

O que se percebe nessa situação é que o empregado fica exposto a qualquer risco provocado por agentes nocivos dentro do ambiente de trabalho, e desprovidos de qualquer segurança que deveria existir obrigatoriamente dentro das empresas. E nesse sentido, o Ministério do Trabalho $9 \mathrm{e}$ Emprego lançou em $2015^{10}$ a Estratégia Nacional para Redução de Acidentes de Trabalho, cujo objetivo é ampliar as ações do governo para reduzir acidentes e as doenças de trabalho a partir de quatro eixos: Intensificação das ações fiscais, pacto nacional para redução de acidentes e doenças do trabalho no Brasil, Campanha nacional de prevenção de acidentes de trabalho e ampliação das análises de acidentes de trabalhos realizados pelos auditores fiscais, melhorando sua qualidade e divulgação,

A não aplicação das infrações por descumprimento dos preceitos legais corrobora para termos essa realidade nos quadros dos acidentes de trabalho, e isso poderia ser evitado se não houvesse certas omissões por parte do estado, por não fiscalizar de forma correta todo e qualquer empreendimento no momento de sua abertura de acordo com o mandamento do art. I6o da CLT. O comando desse artigo determina que os estabelecimentos somente poderão iniciar suas atividades com a prévia inspeção e aprovação de suas instalações pela autoridade regional competente em matéria de segurança e medicina do trabalho.

Percebe-se que cada vez mais se faz necessário os profissionais na área de saúde e segurança do trabalho para que haja uma fiscalização seria nesse sentido, a fim de coibir ou minimizar os abusos por parte das empresas que vilipendiam a classe trabalhadora com maus

\footnotetext{
9 https://agenciabrasil.ebc.com.br/geral/noticia/2015-03/governo-anuncia-plano-de-acao-para-reducao-deacidentes-de-trabalho

ro https://saberalei.jusbrasil.com.br/artigos/34III4233/acidente-do-trabalho-caracteristicas-e-direitos-dotrabalhador
} 
tratos no exercício do labor não demonstrando o respeito, segurança e a saúde exigida por lei.

\section{MEDIDAS PROTETIVAS}

Falar de Medidas Protetivas no ambiente de trabalho, nos remete ao tema Saúde e Segurança do Trabalhado, assunto este, que é tratado pelos profissionais da área utilizandose de muitas regulamentações contidas no ordenamento jurídico brasileiro. Observa que o quadro de normas o qual protege a segurança do trabalhador no ambiente laboral é vasta, entretanto os resultados vultuosos de acidentes, nos leva a entender que não é posta em prática e, portanto não está sendo eficaz.

No que tange a preocupação com o ambiente do trabalho laboral, o artigo $7^{\circ}$, inciso XXII e XXIII da CF/88, vem assegurar como direito fundamental a redução de riscos do trabalho, conforme descreve o Art. 7을 "São direitos dos trabalhadores urbanos e rurais, além de outros que visem à melhoria de sua condição social": e o inciso XXII do mesmo artigo vem complementar "redução dos riscos inerentes ao trabalho, por meio de normas de saúde, higiene e segurança; XXIII - adicional de remuneração para as atividades penosas, insalubres ou perigosas, na forma da lei”.(CF/88).

Evidencia-se que essa preocupação vem estabelecer limites no âmbito do ambiente do trabalho, visando proporcionar ao trabalhador uma maior proteção, vem com o surgimento das grandes sociedades, como bem explica Fiorillo (2013):

[...]O crescimento econômico, se por um lado trazia o desenvolvimento da indústria e do próprio Estado, por outro cuidou de provocar a degradação do meio ante práticas selvagens do capitalismo, preocupado em produzir em grande escala sem atentar para a preservação da qualidade de vida.(FIORILLO,2013)

No que se refere ao risco, Benedito Cardella coloca que "Risco é o dano ou perda esperados no tempo. É uma variável aleatória associada a eventos, sistemas, instalações, processos e atividades. A distribuição de probabilidades do risco é caracterizada pelo valor esperado e pela variância”. (Cardella, 2014, p. 236).

Já no entendimento de NUNES(2014), riscos ambientais são aqueles capazes de alterar as características físicas, químicas e /ou biológicas dos locais de trabalho, colocando em risco especialmente a saúde dos trabalhadores e se classificam em Físicos, químicos e Biológicos (NUNES, 2014, p.162) 
Independentemente da espécie de risco a que o trabalhador esta exposto, caberá à empresa manter efetivo controle para preservar a saúde e a integridade física dos trabalhadores, conforme preconiza o texto constitucional e toda a legislação infraconstitucional. Para tanto, a empresa é obrigada a adotar um efetivo sistema de gestão de segurança e saúde no trabalho. (NUNES, 2014, p.I62).

Nesse sentido, saúde ocupacional são considerados procedimentos adotados pelas empresas que deverão respeitar os princípios éticos, morais e técnicos, na utilização das políticas adequadas objetivando um controle eficaz no alcance da preservação da segurança e saúde para os trabalhadores.

Quanto à segurança define-se como: "Segurança é uma variável inversamente proporcional ao risco. Quanto maior o risco menor a segurança e vice-versa, e aumentar a segurança significa reduzir os riscos”. (Cardella, 2014, p. 237).

Parafraseando Flavio de Oliveira Nunes, segurança no trabalho são medidas que deve ser adotado pelas empresas de forma integrada para eliminar ou neutralizar os riscos existentes no ambiente de trabalho, com a finalidade de preservar a integridade física e a saúde dos trabalhadores.

Tendo como forma de prevenir os riscos inerentes as atividades laborais, as Normas Reguladoras (NRs), são documentos, adotados por uma autoridade com poder legal, com regras de caráter obrigatório para que as empresas cumpram de forma ética sempre agindo com o princípio da boa fé nas relações comerciais quiçá, nas relações de saúde e segurança no trabalho, vez que é direito indisponível do trabalhador exercer suas funções em ambientes livres de quaisquer riscos à saúde como preconiza o texto constitucional no art. $7^{\circ}$, inciso XXII.

O Ministério do Trabalho e Emprego é a autoridade legal para estabelecer as disposições complementares às Normas de Segurança e Saúde no Trabalho, previstas no Capítulo V da CLT, conforme prevê o artigo 200 do texto consolidado.

Art. 200. Cabe ao Ministério do Trabalho estabelecer disposições complementares às normas de que trata este capitulo, tendo em vista as peculiaridades de cada atividade ou setor de trabalho, especialmente sobre: (Redação dada pela Lei no 6.514, de 22.12.1977).I - medidas de prevenção de acidentes e os equipamentos de proteção individual em obras de construção, demolição ou reparos; (Incluído pela Lei no 6.514, de 22.12.1977);II - depósitos, armazenagem e manuseio de combustíveis, inflamáveis e explosivos, bem como trânsito e permanência nas áreas respectivas; (Incluído pela Lei no 6.514, de 22.12.1977);III - trabalho em escavações, túneis, galerias, minas e pedreiras, sobretudo quanto à prevenção de explosões, incêndios, desmoronamentos e soterramentos, eliminação de poeiras, gases, etc. e facilidades de rápida saída dos empregados; (Incluído pela Lei no 6.514, de 22.12.1977);IV - proteção contra incêndio em geral $e$ as medidas preventivas adequadas, com exigências ao especial 
revestimento de portas e paredes, construção de paredes contra-fogo, diques e outros anteparos, assim como garantia geral de fácil circulação, corredores de acesso e saídas amplas e protegidas, com suficiente sinalização; (Incluído pela Lei no 6.514, de 22.12.1977); V - proteção contra insolação, calor, frio, umidade e ventos, sobretudo no trabalho a céu aberto, com provisão, quanto a este, de água potável, alojamento profilaxia de endemias; (Incluído pela Lei $\mathrm{n}$ o 6.514 , de 22.12.1977.(BRASIL-CLTart.200)

Temos as NRs, que são as Normas Regulamentadoras relativas à segurança e medicina do trabalho e determina que seja de observância obrigatória das empresas, sejam elas privadas e ou publicas e também pelos órgãos públicos da administração direta ou indireta, bem como pelos órgãos do Legislativo ou Judiciário, que tenham empregados regidos pela Consolidação das Leis do Trabalho.

O SESMT ${ }^{\text {II }}$ é criação do art. I62, caput, da Consolidação das Leis do Trabalho CLT, e foi regulamentado pela portaria 3.214/ 78 com a publicação da Norma Regulamentadora 04 , que determina que, quaisquer instituições que possuam trabalhadores regidos pela CLT, devem contratar empregados profissionais específicos na área de segurança e medicina do trabalho que possua certo número de empregados. Esse número mínimo de empregados é de cinquenta e os profissionais são: técnico de segurança do trabalho, o engenheiro de segurança do trabalho, o enfermeiro do trabalho e o médico do trabalho.

Deve ser observado ainda o grau de risco da atividade desenvolvida pela empresa que pode ser de um, dois três ou quatro o grau de risco. As empresas que não se enquadram nesses requisitos poderão dar assistência através das instituições privadas custeando todas as despesas.

O Programa de Prevenção de Riscos Ambientais - (PPRA), faz parte de todas as iniciativas das empresas que buscam a saúde e integridade do trabalhador no ambiente do trabalho através da antecipação, reconhecimento e controle dos riscos ambientais e está interligado diretamente com as demais NRs, mais precisamente com o Programa de Controle Médico de Saúde Ocupacional - (PCMSO) previsto na NR-7. ${ }^{12}$

\footnotetext{
II No Brasil, os Serviços Especializados em Engenharia de Segurança e Medicina do Trabalho - SESMT são desempenhados por equipe de profissionais, contratados pelas empresas, com a finalidade de promover a saúde e proteger a integridade física dos trabalhadores. https://www.google.com.br/search?q=sesmt+o+que+\%C3\%A9\&sxsrf=ALeKko3joRQCAhzDW - -

${ }^{12}$ http://www.guiatrabalhista.com.br/legislacao/nr/nr9.htm\#: :text=9.1.1\%2oEsta\%20Norma\%2oRegulament adora,da\%2ointegridade\%2odos\%2otrabalhadores\%2C\%2oatrav\%C3\%A9s. Normas reguladoras.
} 
Note que as Normas Regulamentadoras são de observância obrigatória para todas as empresas públicas, privadas, pelos órgãos da administração pública direta e indireta e também pelos órgãos judiciários e legislativos, que admitam empregados regidos pela Consolidação das Leis do Trabalho. Todas as empresas deverão como forma de prevenção dos riscos adotarem medidas de controle através de planejamento estratégico com etapas de antecipação dos riscos envolvendo a análise de novas instalações, métodos, ou processos de trabalho ou modificar os já existentes, visando identificar os riscos potenciais e introduzir medidas de proteção para sua redução ou eliminação.

Reconhecer os riscos, sua localização e as fontes geradoras, quem está exposto e as medidas já tomadas e constantemente avaliar para se ter o controle dos riscos iminentes são ações que deverão ser feitas pelas empresas constantemente em toda área que contenha empregados de qualquer natureza.

De acordo com Maranhão (2020, p. 163), O Brasil é um dos recordistas mundiais em acidentes de trabalho. Em flagrante paradoxo a esses dados, constata-se que o nosso país contém uma das legislações mais avançadas e pormenorizadas em matéria de saúde do trabalhador.

Logo, é possível asseverar que o problema brasileiro não é normativo, mas proveniente da cultura empresarial, mercantil e imediatista que resiste à ideia de prevenção de acidentes. A infortunística é tratada com menoscabo por parte de boa parte dos operadores jurídicos. Conforme assinalou o Min. Orozimbo Nonato, em decisão histórica do STF proferida em 1949, citado por (Belmonte; Martinez; Maranhão,2020, p.163) a lógica deve ser outra: "É dever do empregador zelar pela segurança, saúde e higiene de seus empregados com a diligência que costuma ter com a própria integridade física e psíquica.” (STF, RE n. I0.39I, Rel. Min. Orozimbo Nonato, DJ I8.8.1949, p. 2.484).

Percebe-se com isso que o empregador tem a obrigação de zelar pela conservação da saúde de seus empregados, sendo que quanto maior for a exposição do empregado a riscos ambientais do trabalho, maior deverá ser o cuidado e a prevenção de acidentes.

\section{I As medidas preventivas no ambiente de trabalho no contexto da covid-ig}

Estamos vivenciando um momento da propagação vertiginosa do COVID-I9, que desde o início do ano de 2019, impôs ao mundo uma série de medidas restritivas por parte dos 
governos de países do mundo todo. Toda a atenção está e continua ainda voltada para os desafios impostos aos sistemas de saúde, em todos os setores.

A pandemia que ora assola o planeta Terra, apesar de não se conhecer completamente o vírus (Covid-I9), nem saber com precisão os efeitos que provoca a saúde do indivíduo, é possível implantar medidas que visem a evitar uma disseminação, com base no que a ciência médica já possui como o distanciamento social, o uso de máscaras pelas pessoas, o uso de álcool a 70\% e lavagem constante das mãos. "Neste caso inexiste conhecimento científico suficiente sobre o vírus e os efeitos sobre a saúde do homem, todavia é possível tomar precaução e prevenção para que não se propague”. (LAVIELLE, 20oI, p.I45, apud

Belmonte; Martinez; Maranhão, 2020, p.166)

Nesse sentido, vale lembrar que o princípio da prevenção e da precaução tem suas raízes em dois princípios fundantes da República brasileira: o da dignidade e o da valorização do trabalho insculpidos no art. ıo, III e IV da Constituição. Por outro lado, guarda estreita conexão com o direito ao meio ambiente ecologicamente equilibrado, no qual se inclui o de trabalho (art. 200 da Constituição de 1988), e com o direito a saúde (art.196/art.20o, da Constituição do Brasil.)

Nesse mesmo diapasão, foi publicada no dia 18/06/2020, uma Portaria Conjunta no 20 da Secretaria Especial de Previdência e Trabalho do Ministério da Economia e do Ministério da Saúde ${ }^{13}$ que estabelece medidas a serem observadas pelas organizações públicas e privadas visando a prevenção, controle e mitigação dos riscos de transmissão da covid-19 nos ambientes de trabalho.

Tendo em vista o disposto na Lei no 13.979, de o6 de Fevereiro de 2020, que dispõe sobre as medidas para enfrentamento da emergência de saúde pública de importância internacional decorrente do coroanvirus ( COVID-19) responsável pelo surto de 2019 e que ora se transformou numa pandemia que está assolando todo o mundo, a aplicação de algumas medidas necessárias:

Art. I $^{\circ}$ Aprovar, na forma prevista no Anexo I desta Portaria, as medidas necessárias a serem observadas pelas organizações visando à prevenção, controle e mitigação dos riscos de transmissão da COVID-19 em ambientes de trabalho, de forma a preservar a segurança e a saúde dos trabalhadores, os empregos e a atividade econômica.

§ Iํ As medidas previstas nesta portaria não se aplicam aos serviços de saúde, para os quais devem ser observadas as orientações e regulamentações específicas, e

${ }^{13}$ https://www.in.gov.br/en/web/dou/-/portaria-conjunta-n-20-de-18-de-junho-de-2020-262408085 
poderão ser revistas ou atualizadas por meio de portaria conjunta, a qualquer momento em razão dos avanços no conhecimento e controle da pandemia.(PORTARIA CONJUNTA №20. 18/o6/2020)

A pandemia do coronavírus trouxe incertezas e consequências serias para o mercado de trabalho, no entanto se faz necessário que as orientações mencionadas pela Portaria de no 20 sejam cumpridas, conforme disposto no artigo $2^{-}$, o qual reza não autorizar o descumprimento pelas organizações:

I - das normas regulamentadoras de segurança e saúde no trabalho;

II - das demais regulamentações sanitárias aplicáveis;

III - de outras disposições que, no âmbito de suas competências, sejam incluídas em regulamentos sanitários dos Estados, Distrito Federal ou Municípios; e

IV - de medidas de saúde, higiene e segurança do trabalho oriundas de convenções e acordos coletivos de trabalho.( Art.2 ${ }^{\circ}$ Portaria $\mathrm{n}^{\mathrm{O}}{ }_{20.2020}$ ).

$\mathrm{O}$ artigo $3^{\mathrm{o}}$ da referida Portaria vem tratar sobre as orientações setoriais complementares. E nesse sentido, a organização deve estabelecer e divulgar orientações ou protocolos com a indicação das medidas necessárias para prevenção, controle e mitigação dos riscos de transmissão da Covid-19 nos ambientes de trabalho, os quais devem estar disponíveis para os trabalhadores. Além disso, devem proceder conforme as orientações abaixo: ${ }^{14}$

- Triagem na entrada das instalações em todos os turnos de trabalho de funcionários e terceirizados, podendo utilizar medição de temperatura.

- Fornecimento de máscaras cirúrgicas ou de tecido para todos os trabalhadores e seu uso obrigatório em ambientes compartilhados ou naqueles em que haja contato com outros trabalhadores ou público.

- Distância mínima de um metro entre os trabalhadores e entre os trabalhadores e o público.

- Adoção de medidas para limitação de ocupação de elevadores, escadas e ambientes restritos, incluindo instalações sanitárias e vestiários.

- Adoção de medidas para distribuir a força de trabalho ao longo do dia, evitando concentrações nos ambientes de trabalho.

- Ações para higiene, ventilação, limpeza e desinfecção dos ambientes.

- Atenção especial a colaboradores que façam parte do grupo de risco, priorizandose, nestes casos, o trabalho remoto ou, ainda, em atividade ou local que reduza o contato com outros trabalhadores e o público, quando possível.

- Promoção do trabalho remoto, quando possível.

- Ações para identificação precoce e afastamento dos trabalhadores com sinais e sintomas compatíveis com a Covid-ig.

9-https://dpc.com.br/covid-rg-medidas-preventivas-no-ambiente-de-trabalho-na-retomada-das atividades $/ 24 / 06 / 2020$ 


\begin{abstract}
- Protocolos para lidar com a ocorrência de casos confirmados, casos suspeitos ou contactantes de casos de Covid-rig.

- Procedimentos para que os trabalhadores possam reportar à organização, inclusive de forma remota, sinais ou sintomas compatíveis com a Covid-19 ou contato com caso confirmado da Covid-rg.

- Instruções sobre higiene das mãos higienização correta e frequente das mãos e etiqueta respiratória.( portaria-conjunta-n-20-de-18-de-junho-de-2020)
\end{abstract}

Entende-se que todas essas precauções se devem ao fato da principal forma de transmissão do coronavírus, que é de pessoa para pessoa. Pode ser por meio de contato próximo com secreções contaminadas e eliminadas na tosse, espirro, fala. Também por contato com objetos e superfícies contaminadas.

Vale ressaltar que a prevenção está ligada a noção de dignidade da pessoa humana, a valorização do trabalho e ao direito saúde. E sendo a dignidade da pessoa humana, valor supremo do constitucionalismo hodierno e um dos princípios estruturantes da nossa República art.ıo,III, como tal, deve estar presente em todas as relações que se travam-no meio social, sujeito a ordem jurídica nacional.

De acordo com Organização Mundial de Saúde-(OMS $\left.{ }^{15}\right)$, o risco de transmissão depende de como ocorreu a exposição ao vírus, de quanto tempo a exposição durou e se foram utilizadas medidas preventivas. E, baseada nessas observações, a OMS traça estratégias de prevenções eficazes e classifica as atividades laborais em três níveis de risco:

risco baixo: atividades que não envolvem contato próximo com o público e/ou
colegas de trabalho e não exigem contato com indivíduos infectados;
risco médio: atividades que envolvem contato próximo com o público e/ou colegas
de trabalho, mas não exigem contato com indivíduos infectados;
risco alto: atividades com alto potencial de contato com indivíduos
infectados. (OMS-2020).

De uma análise atenta, percebe-se que todas as normas de segurança têm o objetivo de prevenção e precaução. Contudo, elas não são exaurientes, mas exemplificativas. representam pois, um minus de proteção à saúde do trabalhador, e devem ser complementadas com o dever geral de cautela (prevenção e precaução).

Diante do exposto, Tupinambá(2020), vem acrescentar que:

A pandemia do novo coronavírus chegou abruptamente em 2019/2020 e vai marcar uma época, provocando mudanças acentuadas e adaptações inevitáveis[,,,] já se vislumbra nas cogitações do momento que não haverá o desejável retorno ao

\footnotetext{
${ }^{15}$ https://coronavirus.saude.mg.gov.br/blog/152-coronavirus-no-trabalho
} 
normal, uma vez que estamos ingressando inevitavelmente no desconhecido território de um novo normal.(TUPINAMBÁ, 2020. p.I44).

Assevera ainda sobre a importância de caracterizar "a COVID-ı9 como doença ocupacional, observando a Constituição Federal no que confere aos trabalhadores no artigo $7^{\circ}$, XXVIII, o direito dos benefícios do seguro contra acidente de trabalho, devendo o trabalhador que foi vítima do covid-19 observar o que está previsto em uma das hipóteses que a Lei Previdenciária no 8.213/199I considera como doença relacionada ao trabalho.

\section{CONCLUSÃO}

Ante o exposto, conclui-se que o objetivo maior de todo o ordenamento jurídico que protege a saúde e segurança do trabalho, é o de cada vez mais proporcionar um ambiente de trabalho salutar, primando pela vida do trabalhador como ponto central, garantindo o direito fundamental e a dignidade da pessoa humana em todas as suas dimensões sociais, físicas e psicológicas dentro e fora do local de trabalho.

Considerando que a vida no trabalho interfere não somente no desenvolvimento produtivo do trabalho, mas em todos os outros segmentos da vida do trabalhador no campo familiar e social, as empresas devem atender as exigências por obrigação dos comandos normativos articulando suas ações com os outros seguimentos existentes específicos capazes de contribuir para o cumprimento dos direitos humano atendendo as necessidades físicas, psicológica e social de todo trabalhador.

Muito já foi feito com relação a segurança e saúdo do trabalhador no ambiente de trabalho, mas há ainda muito a se fazer com relação a garantir o respeito aos direitos humanos no trabalho direito esse indisponível e inalienável.

Vale ressaltar que no atual cenário de incertezas, em meio a pandemia do coronavirus, que além das doenças e riscos advindos do meio ambiente do trabalho ainda temos a preocupação inerente ao enfrentamento do covid-ı9 que trouxe várias consequências sobre o mercado de trabalho, dentre elas a diminuição de renda em alguns casos e o desemprego.

No entanto, deve-se priorizar a vida seguindo as normativas elencadas e pensando mais no coletivo, na valorizar o homem enquanto ser humano e sujeito de direitos. 
Evidencia-se ainda que o Brasil é um dos recordistas mundiais em acidentes de trabalho, mas por outro lado, o nosso país contém uma das legislações mais avançadas e pormenorizadas em matéria de saúde do trabalhador. Nesse sentido, não basta a previsão do PPRA e PCMSO, mas o apontamento e cumprimento de medidas capazes de elidir ou reduzir o risco ocupacional, é preciso que o empregador tenha a obrigação de zelar pela conservação da saúde de seus empregados, sendo que quanto maior for a exposição do empregado a

Riscos ambientais do trabalho, maior deverá ser o cuidado e a prevenção de acidentes.

E partindo dessa premissa de que o local de trabalho, é por sua vez, o ambiente onde o trabalhador passa a maior parte de sua vida, e considerando que, o bem mais caro para todo e qualquer ser vivente é a vida, fica subentendido que deve ser um lugar seguro, digno, capaz de garantir aos trabalhadores os direitos fundamentais humanos como determina a Carta Magna de 88.

\section{REFERÊNCIAS BIBLIOGRÁFICAS}

AGUIAR, Antonio Carlos. O vetor constitucional da solidariedade em tempos de coronavírus. In: BELMONTE, Alexandre de Souza Agra; MARTINEZ, Luciano; MARANHÃO, Ney Stany Morais (org.). Direito do Trabalho na Crise da Covid-I9, Salvador, p. IOI - II2, 2020. Disponível em: https://especial.editorajuspodivm.com.br/ebookdireito-trabalho-covidi9. Acesso em 26 jan. 2021.

BRASIL. Constituição (1988). Constituição da República Federativa do Brasil.

BRASIL. Consolidação das Leis do trabalho. Decreto-lei no 5.452 , de $\mathrm{I}^{\mathrm{o}}$ de maio de 1943 . Aprova a Consolidação das Leis do Trabalho. Disponível em: . Acesso em: Io ago. 2017.

CARDELLA, Benedito.Segurança no Trabalho e Prevenção de Acidentes: Uma Abordagem Holística. São Paulo: Atlas, 2014.

FIORILlO. Celso Antônio Pacheco. Curso de Direito Ambiental Brasileiro. I4 ${ }^{a}$ ed. rev. ampl. e atual. São Paulo: Saraiva, 2013.

GARCIA, Gustavo Filipe Barbosa. Curso de Direito do Trabalho. 8. ed. Rio de Janeiro: Forense, 20I4.

LAVILlE, C.; DIONE, J. A construção do saber. Porto Alegre: Artes Médicas Sul; Belo Horizonte: UFMG, 1999

MARTINS, Sergio Pinto. Comentários à CLT. 18. ed. São Paulo: Atlas, 2014. 
NUNES, Flavio de Oliveira. Segurança e Saúde no Trabalho Esquematizado. 2. ed. São Paulo: Método, 2014.

TUPINAMBÁ, Carolina (coord.)As novas relações trabalhistas e o futuro do direito do trabalho. Novidades derivadas da pandemia da covid-ı e da crise de 2020.. Belo Horizonte. Fórum, 2021.

http://www.tst.jus.br/web/trabalhoseguro/dados-nacionais

https://www.sinait.org.br/?r=site/noticiaView \&id $=8346$

MARANHÃO, Ney. Alexandre Agra, Belmonte, Luciano Martinez,. O Direito do Trabalho na crise da COVID-ı9 - Salvador: Editora JusPodivm, 2020.

NASCIMENTO, Amauri Mascaro. Curso de Direito do Trabalho, 29- ed. São Paulo: Saraiva, 2014.

〈http://www.pgt.mpt.gov.br/publicacoes/seguranca/resp_acidente_trab.pdf $>$ Acesso em io set. 2017. 